BMJ Open

Diabetes

Research

\& Care

\title{
Clinician prescription of lipid-lowering drugs and achievement of treatment goals in patients with newly diagnosed type 2 diabetes mellitus
}

\author{
Ana Cristina García-Ulloa (D) , , ${ }^{1,2}$ Claudia Lechuga-Fonseca, ${ }^{2}$ \\ Fabiola Mabel Del Razo-Olvera, ${ }^{3}$ Carlos Alberto Aguilar-Salinas (D) ,3,4,5 \\ Karla Ivette Galaviz, ${ }^{6}$ K M Venkat Narayan (D) , ${ }^{6}$ Sergio Hernández-Jiménez (D) , ,,2 \\ On behalf of Group of Study CAIPaDi
}

To cite: García-Ulloa AC, Lechuga-Fonseca $\mathrm{C}$, Del Razo-Olvera FM, et al. Clinician prescription of lipid-lowering drugs and achievement of treatment goals in patients with newly diagnosed type 2 diabetes mellitus. BMJ Open Diab Res Care 2021;9:e001891. doi:10.1136/ bmjdrc-2020-001891

Received 23 November 2020 Revised 24 December 2020 Accepted 30 December 2020
Check for updates

(c) Author(s) (or their employer(s)) 2021. Re-use permitted under CC BY-NC. No commercial re-use. See rights and permissions. Published by BMJ.

For numbered affiliations see end of article.

\section{Correspondence to} Dr Sergio Hernández-Jiménez; sergio.hernandezj@incmnsz. $\mathrm{mx}$

\section{ABSTRACT}

Introduction Lipid control is essential in type 2 diabetes mellitus (T2DM). The aim of this study is to investigate factors associated with lipid therapy adherence and achievement of goals in real-life setting among patients with recently diagnosed T2DM.

Research design and methods This is a longitudinal analysis in a center of comprehensive care for patients with diabetes. We include patients with T2DM, $<5$ years of diagnosis, without disabling complications (eg, amputation, myocardial infarct, stroke, proliferative retinopathy, glomerular filtration rate $<60 \mathrm{~mL} / \mathrm{min} / \mathrm{m}^{2}$ ) and completed 2-year follow-up. The comprehensive diabetes care model includes 9 interventions in 4 initial visits and annual evaluations. Endocrinologists follow the clinic's guideline and adapt therapy to reach riskbased treatment goal. The main outcome measures were the proportion of patients meeting low-density lipoprotein cholesterol (c-LDL) (<100 mg/dL) and triglycerides (<150 mg/ $\mathrm{dL}$ ) and proportion of patients taking statin, fibrate or combination at baseline, 3 months and annual evaluations. Results We included 288 consecutive patients $(54 \pm 9$ years, $53.8 \%$ women), time since T2DM diagnosis $1(0-5)$ year. Baseline, $10.8 \%$ patients were receiving statin therapy (46.5\% moderate-intensity therapy and $4.6 \%$ high-intensity therapy), $8.3 \%$ fibrates and $4.2 \%$ combined treatment. The proportion of patients with combined treatment increased to $41.6 \%$ at 3 months, decreased to $20.8 \%$ at 1 year and increased to $38.9 \%$ at 2 years of evaluation. Patients receiving treatment met LDL and triglycerides goals at 3 months (17\% vs $59.7 \%$, relative ratio $(\mathrm{RR})=0.89,95 \% \mathrm{Cl} 0.71$ to 1.12$)$, at 1 year $(17 \%$ vs $26.7 \%, \mathrm{RR}=0.62,95 \% \mathrm{Cl} 0.41$ to 0.95$)$ and at 2 years $(17 \%$ vs $29.9 \%, \mathrm{RR}=0.63,95 \% \mathrm{Cl} 0.43$ to 0.93 ). Main reasons for medication suspension: patient considered treatment was not important (37.5\%) and other physician suspended treatment (31.3\%).

Conclusion $88.2 \%$ of patients with T2DM required lipidlowering drugs. Education for patients and physicians is critical to achieve and maintain diabetes goals. Trial registration number NCT02836808.

\section{INTRODUCTION}

Lipid abnormalities such as elevated total cholesterol and triglycerides, low high-density

\section{Significance of this study}

What is already known about this subject?

- Lipid abnormalities are common in patients with type 2 diabetes mellitus.

- Medication adherence plays a major role in achieving lipid control.

- For patients with chronic conditions, adherence remains suboptimal causing significant costs.

- Discontinuation or non-compliance with lipidlowering treatments, lack of adherence to guidelines, previous adverse effects, clinical inertia or preference for behavioral changes first are the main factors associated with uncontrolled lipid goals.

What are the new findings?

$>$ On admission, $77 \%$ did not receive any lipidlowering medication.

- This proportion changed after following established treatment algorithms.

- The main reasons for not receiving treatment were hypothyroidism without levothyroxine treatment, use of drugs that cause dyslipidemia or allergy reported to the substances.

- The most common dose of atorvastatin was $10 \mathrm{mg}$, to achieve low-density lipoprotein cholesterol goal.

- The main causes of suspended treatment were the same for statins and fibrates.

- The most common reasons were because patients considered it was not important for their control and because their treating physician changed the treatment.

How might these results change the focus of research or clinical practice?

- These results can help to establish strategies to improve drug therapy adherence to achieve and maintain metabolic goals.

lipoprotein cholesterol (HDL-C) cholesterol and a predominance of small, dense low-density lipoprotein cholesterol (LDL-C) 
particles $^{1}$ are common in patients with type 2 diabetes mellitus (T2DM). Medication adherence, described as the extent to which patients take their medications as prescribed, plays a major role in achieving lipid control. Treating a symptomless disease such as diabetes and hyperlipidemia presents a remarkable challenge. ${ }^{2}$ For patients with chronic conditions, adherence remains suboptimal causing significant costs, ${ }^{3}$ and has been recognized as a public health problem. ${ }^{4}$ Discontinuation or non-compliance with lipid-lowering treatments is likely to be a complex phenomenon in which the physician, the patient, various comorbidities and the characteristics of the prescribed medications may play a role. ${ }^{5}$

The high prevalence of dyslipidemia and low rate of its control in Mexico is a challenge. ${ }^{6}$ The National Health Survey from Mexico (2006) reported that only $28.6 \%$ of patients with diabetes had LDL levels $<100 \mathrm{mg} / \mathrm{dL}^{7}$ Another National Health Survey from Mexico (2016) reported that $44.5 \%$ of patients measured blood cholesterol levels once in their lives, and only $28 \%$ received a previous diagnosis of dyslipidemia. ${ }^{8}$ Lowering cholesterol levels in recent years are attributable to greater use of cholesterol-lowering drugs rather than dietary changes. Statins are the first-line treatment for elevated LDL-C levels and fibrates are first-line therapy for hypertriglyceridemia. ${ }^{910}$ Poor statin adherence has been reported in up to $50 \%$ of patients, discontinuation rates are around $15 \%$ and changing to lower potency statin therapy has been noted in up to $42 \%$ of patients. ${ }^{11-13}$ Many factors have been linked to poor adherence, such as lack of information about the potential benefits of therapy, denial, adverse effects, impaired memory, discontinuation, dose reduction, statin switching and non-acceptance to therapy. ${ }^{2}{ }^{14}$ Reasons for not prescribing lipid-lowering medications include lack of adherence to guidelines, previous adverse effects, clinical inertia or preference for behavioral changes first. ${ }^{15}$ There is a lack of information about adherence to lipid-lowering therapy in newly diagnosed diabetes in a real-life setting. Here, we investigate the association between lipid-lowering drug prescription and adherence with lipid control among patients with recently diagnosed diabetes.

\section{MATERIALS AND METHODS}

CAIPaDi program

Details about the CAIPaDi model have been published elsewhere. ${ }^{15}{ }^{16}$ Briefly, CAIPaDi is a comprehensive diabetes care model that consists of two phases. The first phase comprises a baseline visit followed by 3 monthly visits where patients are attended by nine different specialists (endocrinologists, diabetes educator, nutritionist, psychologist, dentist, psychiatrist, ophthalmologist, physical therapist and foot care expert). After this 3-month phase, patients continue their treatment with their treating physician. For the second phase, patients return to CAIPaDi annually. In each visit, each healthcare professional treats patients following specific protocols for each intervention. Endocrinologists assess maintenance of metabolic control and adjust drug treatment following a treatment algorithm ${ }^{15-18}$ for glucose, lipids and blood pressure control. The algorithm makes treatment recommendations considering economic resources of the patient. During these visits, information about the importance of metabolic control and treatment adherence for a long-term is also provided to patients. The CAIPaDi model was approved by the Institutional Ethics and Research Committees (Ref 1198) and registered in ClinicalTrials.gov (NCT02836808). All patients signed an informed consent form.

\section{Study design and sample}

This was a longitudinal study of data collected in the CAIPaDi program. CAIPaDi patients with T2DM, with $<5$ years of diagnosis, body mass index $\leq 45 \mathrm{~kg} / \mathrm{m}^{2}$, non-smokers, without disabling chronic complications (amputations, myocardial infarction, stroke, glomerular filtration rate $<60 \mathrm{~mL} / \mathrm{min} / \mathrm{m}^{2}$ ) were included. In this analysis we included all patients who finished their 2 years evaluation.

\section{Measures}

Fasting concentrations of cholesterol, triglycerides and HDL-C (Bio-Rad Variant II Turbo Hemoglobin A1c Kit 2, with high-pressure liquid chromatography method) were assessed in each visit. The laboratory is certified by ISO 90001:2015 and the College of American Pathologist.

The cholesterol goal was LDL $<100 \mathrm{mg} / \mathrm{dL}$ consistent with primary prevention in the American College of Cardiology/American Heart Association 2013 guidelines ${ }^{19}$ to achieve a $30 \%-50 \%$ reduction in LDL levels. The triglyceride goal was $<150 \mathrm{mg} / \mathrm{dL}$, based on American Diabetes Association Standards of Care. ${ }^{20}$

We also estimated the proportion of patients taking a statin (St), fibrate (Fib) or combinations (St+Fib). All measures are conducted at baseline (V0), the first visit (V1), at 3 months (V4), at 1 year (V5) and at 2 years (V6). Statins indicated were moderate intensity to achieve a $30 \%-50 \%$ reduction.

\section{Statistical analysis}

Results were reported as means $( \pm \mathrm{SD})$ if they followed a normal distribution or medians and IQRs (25-75) if they did not have a normal distribution, according to Kolmogorov-Smirnov test. Percentages were used for discrete values. Changes in the percentages of patients were compared using McNemar test. Analysis by protocol was performed and included T-test for related samples. Analysis included T-test or Mann-Whitney U test for related samples when appropriate to analyze changes in lipid parameters between visits. SPSS Statistics V.21 was used for data analysis and point differences with $95 \%$ CIs are reported for all comparisons between variables. 
Table 1 Changes in metabolic parameters at basal, 3 months and 1 year and treatment indicated

\begin{tabular}{|c|c|c|c|c|c|c|c|c|c|}
\hline & & & \multicolumn{2}{|c|}{$\begin{array}{l}\text { Basal parameters } \\
\text { (V0) }\end{array}$} & \multicolumn{2}{|c|}{$\begin{array}{l}\text { Lipids at } 3 \text { months } \\
\text { (V4) }\end{array}$} & \multicolumn{2}{|c|}{$\begin{array}{l}\text { Lipids at 1-year follow- } \\
\text { up (V5) }\end{array}$} & $\begin{array}{l}\text { Lipids at 2-year } \\
\text { follow-up (V6) }\end{array}$ \\
\hline \multicolumn{3}{|c|}{ Triglycerides $†$ (mg/dL) } & \multicolumn{2}{|c|}{169 (122-248) } & \multicolumn{2}{|l|}{$111(86-147)$} & \multicolumn{2}{|c|}{141 (103-195) } & 138 (105-188) \\
\hline \multicolumn{3}{|c|}{ LDL cholesterol† (mg/dL) } & \multicolumn{2}{|l|}{$115 \pm 38$} & \multicolumn{2}{|l|}{$85 \pm 24$} & \multicolumn{2}{|l|}{$109 \pm 33$} & $106 \pm 31$ \\
\hline \multicolumn{10}{|c|}{ LDL cholesterol† (mg/dL) } \\
\hline$\geq 50$ years old & Basal & $\begin{array}{l}\text { Tree } \\
\text { indi } \\
\text { the }\end{array}$ & $\begin{array}{l}\text { atment } \\
\text { icated in } \\
\text { first visit }\end{array}$ & $\begin{array}{l}\text { Treatment } \\
\text { indicated } \\
\text { in visit } 4 \text { (3 } \\
\text { months) (\%) }\end{array}$ & $\begin{array}{l}\text { How patients } \\
\text { arrive at } 1-y e a r \\
\text { follow-up }(\%)\end{array}$ & $\begin{array}{l}\text { Treat } \\
\text { indic } \\
\text { first } \\
(\%)\end{array}$ & $\begin{array}{l}\text { nent } \\
\text { ted in the } \\
\text { nnual visit }\end{array}$ & $\begin{array}{l}\text { How } \\
\text { patients } \\
\text { arrive at } 2 \\
\text { years (\%) }\end{array}$ & $\begin{array}{l}\text { Treatment } \\
\text { indicated in the } \\
\text { second annual } \\
\text { visit (\%) }\end{array}$ \\
\hline $\begin{array}{l}\text { Only fibrates } \\
(\%)\end{array}$ & 8.3 & 13. & & 12.2 & 11.1 & 7.6 & & 9.7 & 7.3 \\
\hline $\begin{array}{l}\text { Statin } \pm \text { fibrate } \\
(\%)\end{array}$ & 4.2 & 30.2 & & $41.6^{*}$ & $20.8 \ddagger$ & 40.6 & & $20.1 \ddagger$ & 38.9 \\
\hline
\end{tabular}

${ }^{*} \mathrm{P}<0.001$ comparing with basal evaluation (V0).

†Analysis of variance for lipid control parameters $p<0.001$.

$\ddagger \mathrm{P}<0.001$ compared with previous visit.

LDL, low-density lipoprotein.

\section{RESULTS}

In this report, we included 288 patients who finished their second annual evaluation of the CAIPaDi program. The mean age was $54 \pm 9$ years, $53.8 \%$ were women, with a median time since diagnosis of 1 year. The percentage of patients treated with lipid-lowering agents and lipid concentrations are shown in table 1. At baseline, $10.8 \%$ patients were receiving statin therapy $(46.5 \%$ moderateintensity therapy $/ 4.6 \%$ high-intensity therapy), $8.3 \%$ fibrates and $4.2 \%$ combined treatment. The most frequent lipid-lowering drugs used were atorvastatin (10 $\mathrm{mg}(10-20 \mathrm{mg}))$ and bezafibrate (200 mg (200-400 mg)).

On admission, $76.7 \%$ did not receive any lipid-lowering medication. This proportion changed to $11.8 \%$ at 3 months because they were in good control (low-density lipoprotein cholesterol (LDL-C) $85 \pm 24 \mathrm{mg} / \mathrm{dL}$ and triglycerides $111 \mathrm{mg} / \mathrm{dL}(84-147 \mathrm{mg} / \mathrm{dL}))$. At visit 4 (3 months), around $40 \%$ received combined treatment (St+Fib). At 1 and 2 years, 60 and $75 \%$ of the patients requires treatment with $\mathrm{ST}$ and $\mathrm{St}+\mathrm{Fib}$. The median of triglycerides in the studied population remained in the control goal.

We divided the patients in four groups for triglyceride and LDL-C control: 1) patients that do not require treatment, 2) on LDL-C target taking drugs, 3) above LDL-C target despite taking drugs, and 4) bad control without treatment. The fourth group show the percentage of patients in control and bad control with or without lipid lowering treatment in each visit.

The main reasons for not receiving treatment were hypothyroidism without levothyroxine treatment, use of drugs that cause dyslipidemia or allergy to statins. The proportion of patients who continued statin treatment at 3 months was $76 \%$. When they were evaluated at 1 year, this percentage decreased to $40.6 \%$. These percentages were similar for the 2-year evaluation (42.7\% continued taking statins and was indicated in $75 \%$ at the end of the visit). Tables 2 and 3 show the percentage of patients in control and bad control with or without lipid lowering treatment in each visit.

Table 4 shows the distribution of lipid-lowering drugs in patients aged $<50$ and $>50$ years. The proportion of patients treated with only Fib is constant. Almost half of the patients having suspended lipid-lowering treatment attend annual check-ups. This was similar in patients over and under 50 years of age. In around half of the patients, statins were prescribed in $78 \%$ at 1 year.

At the initial visit, a low percentage of patients do not require treatment, which increases at the end of the 3-month period. For triglyceride control, 43.1\% of patients do not require treatment in the 3-month evaluation, but for the annual visits, this percentage stays steady. For LDL-C where $43.1 \%$ of patients do not require treatment in the 3-month evaluation and stays 
Table 2 Percentage of patients in control and bad control of triglycerides with or without fibrate treatment in each visit

\begin{tabular}{|c|c|c|c|c|c|}
\hline & $\begin{array}{l}\text { Basal (before } \\
\text { intervention) }\end{array}$ & $\begin{array}{l}\text { With treatment } \\
\text { indicated in the } \\
\text { first visit }\end{array}$ & $\begin{array}{l}\text { Evaluation at } 3 \\
\text { months visit (\%) }\end{array}$ & $\begin{array}{l}\text { Evaluation at } \\
1 \text {-year follow-up } \\
(\%)\end{array}$ & $\begin{array}{l}\text { Evaluation at 2-year } \\
\text { follow-up (\%) }\end{array}$ \\
\hline Treatment and control & 5.6 & 5.6 & 32.6 & 15.6 & 14.9 \\
\hline $\begin{array}{l}\text { Treatment and bad } \\
\text { control }\end{array}$ & 0 & 6.9 & 21.2 & 16.3 & 14.6 \\
\hline $\begin{array}{l}\text { Without treatment and } \\
\text { control }\end{array}$ & 36.1 & 36.1 & 43.1 & 41 & 43.4 \\
\hline $\begin{array}{l}\text { Without treatment and } \\
\text { bad control }\end{array}$ & 58.3 & 51.4 & 3.1 & 27.1 & 27.1 \\
\hline OR (95\% Cl) & $1.15(1.07-1.23)$ & $0.89(0.48-1.65)$ & $2.02(1.69-2.4)$ & $1.35(0.97-1.90)$ & $1.36(0.95-1.95)$ \\
\hline$P$ vaue & $<0.001$ & $<0.001$ & $<0.001$ & $<0.001$ & $<0.001$ \\
\hline
\end{tabular}

constant for annual visits. On the other hand, patients with bad control and requiring treatment changes drastically in annual visits. For triglycerides, only $3.1 \%$ of patients still have levels $>150 \mathrm{mg} / \mathrm{dL}$ and are without treatment (mostly because of borderline results), but changes to $27.1 \%$ of patients uncontrolled and without treatment in the annual evaluations. In the CAIPaDi visit, treatment is adjusted and only $9.4 \%$ and $10.4 \%$ of patients are without treatment in 1 and 2-year visits, respectively.

For LDL-C we observed something similar, where only $3.1 \%$ of patients are still with bad control and not taking statin, but the percentage increases to $27.1 \%$ in annual evaluations (figure 1).

The most common dose of atorvastatin was $10 \mathrm{mg}$. The percentage of patients receiving this dose were $54 \%$ at the beginning, which increased to $62 \%$ in that initial visit depending on LDL-C results, and $41 \%$ of the patients were taking $10 \mathrm{mg}$ at the end of the 3-month period. For annual evaluations, $50.8 \%$ arrived with that dosage, and changed to $53 \%$ of patients. For the 2-year evaluation, $52 \%$ were under atorvastatin $10 \mathrm{mgs}$ treatment and changed to $54 \%$ of the patients $(\mathrm{p}=0.53)$.

\section{Characteristics of patients who abandoned treatment}

The patients who abandoned treatment with fibrates for the first annual evaluation were $54 \pm 8.7$ years of age compared with the patients who did not abandon treatment ( $53 \pm 9.7, \mathrm{p}=0.57$; OR -0.43 ; $95 \%-2.5$ to 1.6$)$.

The time of diagnosis of diabetes was $1(0-3)$ years. For the second annual evaluation, the age of patients who did not abandon fibrates was $54.7 \pm 8.7$ years of age vs $52 \pm 9.4$ years for those who abandoned treatment $(p=0.03)$. The time of diagnosis of diabetes was $1(0-3)$ years for both groups. The patients who abandoned treatment with statins for the first annual evaluation were $54 \pm 9$ years of age compared with the patients who did not abandon treatment who were $53 \pm 9(\mathrm{p}=0.51)$. The time of diagnosis of diabetes was $1(0-3)$ years. For the second annual evaluation, the age of patients who did not abandon statins was $53 \pm 9$ years of age vs $54 \pm 8.9$ years for those who abandoned treatment $(\mathrm{p}=0.42)$. The time of diagnosis of diabetes was $1(0-3)$ years for those who did not abandon statins and $1(0-4)$ for those who abandoned.

The main causes of suspended treatment were the same for statins and fibrates. The most common reasons being because they considered it was not important for their

Table 3 Percentage of patients in control and bad control of LDL-C with or without statin treatment in each visit

\begin{tabular}{|c|c|c|c|c|c|}
\hline & $\begin{array}{l}\text { Basal (before } \\
\text { intervention) }\end{array}$ & $\begin{array}{l}\text { With treatment } \\
\text { indicated in the first } \\
\text { visit }\end{array}$ & $\begin{array}{l}\text { Evaluation at } 3 \\
\text { months visit (\%) }\end{array}$ & $\begin{array}{l}\text { Evaluation at 1- } \\
\text { year follow-up (\%) }\end{array}$ & $\begin{array}{l}\text { Evaluation at } 2- \\
\text { year follow-up (\%) }\end{array}$ \\
\hline $\begin{array}{l}\text { Treatment and bad } \\
\text { control }\end{array}$ & 0 & $20(6.9 \%)$ & $61(21.2 \%)$ & 47 (16.3\%) & $42(14.6 \%)$ \\
\hline $\begin{array}{l}\text { Without treatment and } \\
\text { control }\end{array}$ & 29.3 & $104(36.1 \%)$ & $124(43.1 \%)$ & $118(41.0 \%)$ & $125(43.4 \%)$ \\
\hline $\begin{array}{l}\text { Without treatment and } \\
\text { bad control }\end{array}$ & 63.1 & $148(51.4 \%)$ & $9(3.1 \%)$ & $78(27.1 \%)$ & $78(27.1 \%)$ \\
\hline OR $(95 \% \mathrm{Cl})$ & $1.26(1.14-1.39)$ & $0.89(0.48-1.65)$ & $2.02(1.69-2.4)$ & $1.35(0.97-1.90)$ & $1.36(0.95-1.95)$ \\
\hline $\mathrm{P}$ value & $<0.001$ & $<0.001$ & $<0.001$ & $<0.001$ & $<0.001$ \\
\hline
\end{tabular}

LDL-C, low-density lipoprotein cholesterol. 
Table 4 Distribution of lipid-lowering drugs in patients aged $<50$ and $>50$ years

\begin{tabular}{|c|c|c|c|c|c|c|c|}
\hline & Basal & $\begin{array}{l}\text { Treatment } \\
\text { indicated in } \\
\text { the first visit }\end{array}$ & $\begin{array}{l}\text { Treatment } \\
\text { indicated } \\
\text { in visit } 4(3 \\
\text { months) (\%) }\end{array}$ & $\begin{array}{l}\text { How patients } \\
\text { arrive at 1- } \\
\text { year follow- } \\
\text { up (\%) }\end{array}$ & $\begin{array}{l}\text { Treatment } \\
\text { indicated in } \\
\text { the first annual } \\
\text { visit (\%) }\end{array}$ & $\begin{array}{l}\text { How } \\
\text { patients } \\
\text { arrive at } 2 \\
\text { years (\%) } \\
\end{array}$ & $\begin{array}{l}\text { Treatment } \\
\text { indicated in the } \\
\text { second annual } \\
\text { visit (\%) }\end{array}$ \\
\hline \multicolumn{8}{|l|}{$<50$ years old $(n=80)$} \\
\hline Without treatment (\%) & 82.5 & 31.3 & 17.5 & 51.2 & 21.3 & 48.8 & 22.5 \\
\hline Only statins (\%) & 3.8 & 22.5 & 25 & 13.8 & 20 & 15 & 22.5 \\
\hline Only fibrates (\%) & 11.3 & 16.3 & 17.5 & 11.3 & 8.8 & 12.5 & 11.3 \\
\hline Statin \pm fibrate $(\%)$ & 2.5 & 30 & 40 & 23.8 & 50 & 23.8 & 43.8 \\
\hline \multicolumn{8}{|l|}{$\geq 50$ years old $(n=208)$} \\
\hline Without treatment (\%) & 74.5 & 15.9 & 9.6 & 47.1 & 14.9 & 47.6 & 15.9 \\
\hline Only statins (\%) & 13.5 & 40.9 & 38 & 22.1 & 40.9 & 25.5 & 41.3 \\
\hline Only fibrates (\%) & 7.2 & 13 & 10.1 & 11.1 & 7.2 & 8.2 & 5.8 \\
\hline Statin \pm fibrate (\%) & 4.8 & 30.3 & 42.3 & 19.7 & 37 & 18.8 & 37 \\
\hline
\end{tabular}

control and because their treating physician changed the treatment. The main reasons are shown in figure 2.

\section{DISCUSSION}

We found at the beginning of the study that $76.7 \%$ of the patients did not have lipid-lowering treatment, being that the average LDL-C was $115 \pm 38 \mathrm{mg} / \mathrm{dL}$. This parameter improved at the end of the first phase of the CAIPaDi program. Lipid-lowering therapy has long been an underused therapy to lower cardiovascular risk despite compelling evidence of the effectiveness of this therapy. ${ }^{21}$ The National Multicenter Population Health Examination Survey in Poland showed that only $3 \%$ of patients with hypercholesterolemia achieved the recommended cholesterol levels. ${ }^{22}$ A Spanish study reported that $86.7 \%$ of the patients had an initial out-of-target LDL-C. The percentage of patients with a LDL-C within the objective evolved from $13.3 \%$ at the initial time to $27.5 \%$ at the end of the follow-up $(\mathrm{p}<0.001){ }^{23}$

Although lipid control reduces the risk of coronary heart disease, statin therapy is commonly abandoned. In a study done by Yang et $a l,{ }^{5}$ statin treatment was associated with more treatment continuations when the patients were under many other drug treatments. Different to our study, we found that half of the patients who have prescribed a scheme with St and those with St+Fib discontinued their lipid-lowering treatment. The most frequent lipid-lowering drugs were atorvastatin and bezafibrate since these are economically accessible and potent drugs.

Previous studies have reported guideline adherence among patients with diabetes mellitus as varying between $24 \%$ and $80 \% .^{15}$ In primary prevention, drugs were

\section{A}

Triglycerides control in each visit and vibrate indication

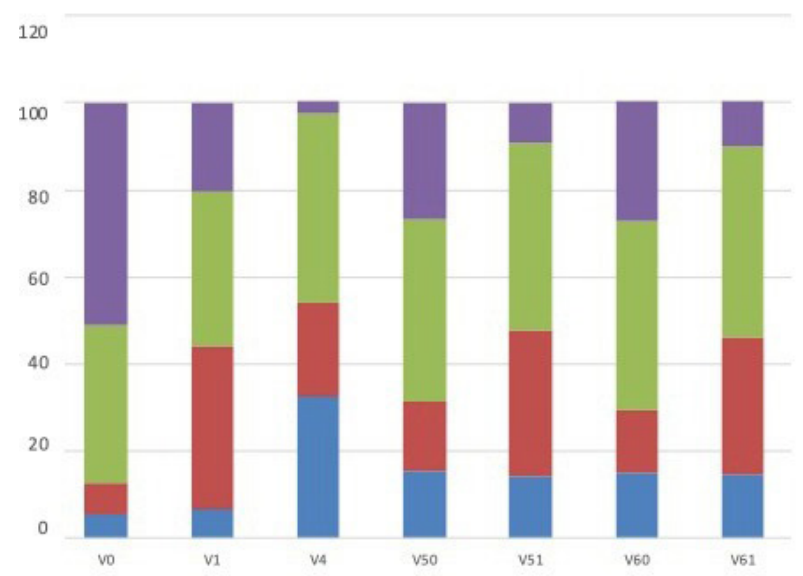

\section{B LDL-c control in each visit and vibrate indication}

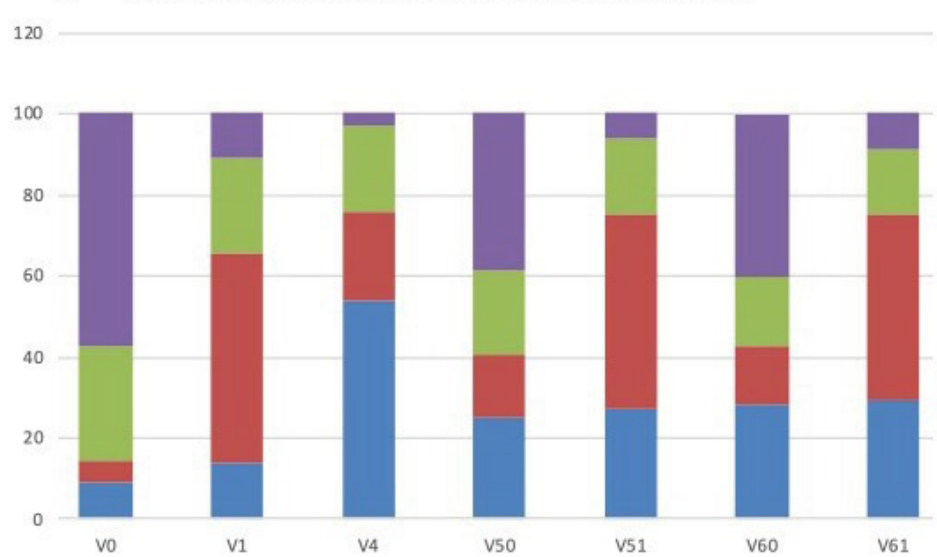

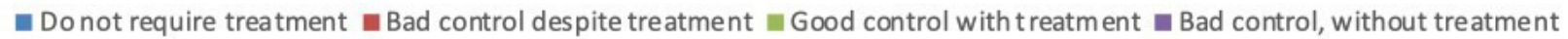

Figure 1 Percentage of patients in control/without control and treatment/without treatment. (A) Control and treatment for triglycerides. (B) Control and treatment for low-density lipoprotein cholesterol (LDL-C). 

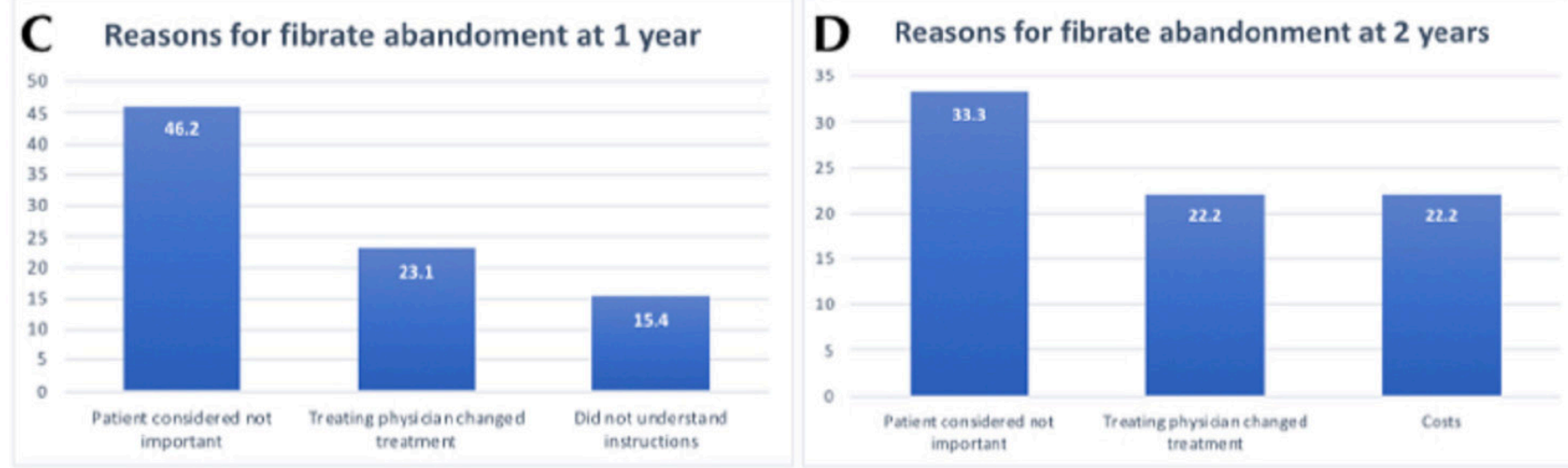

\section{E Reasons for statin+fibrate abandonment at 1 year}

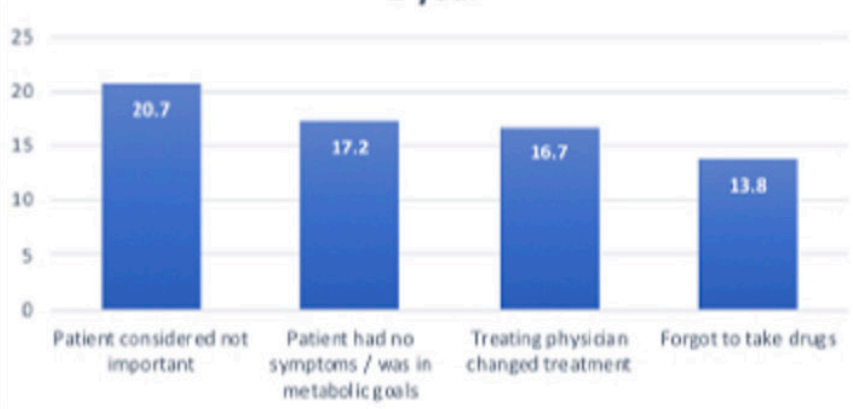

\section{B Reasons for statin abandonment at 2 years}

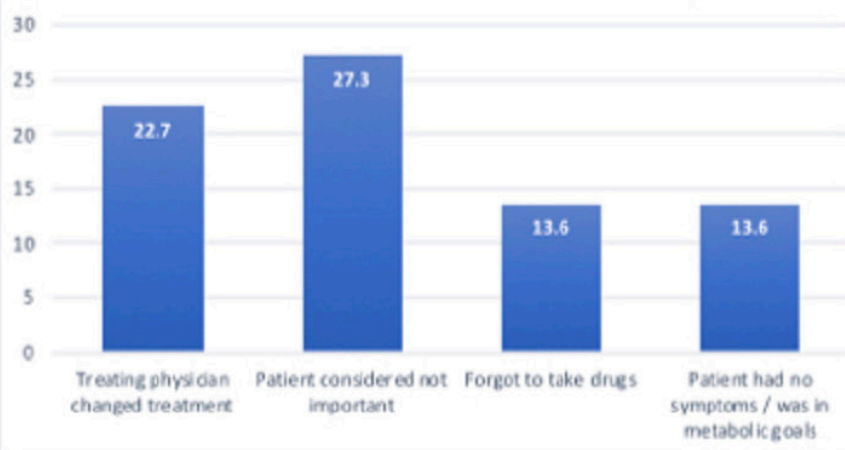

Figure 2 Main reasons for treatment suspension at 1 and 2 years of follow-up. (A) Statin suspension at 1 year; (B) statin suspension at 2 years; (C) fibrate suspension at 1 year; (D) fibrate suspension at 2 years; (E) combination of lipid-lowering drugs suspension at 2 years; (F) combination of lipid-lowering drugs suspension at 2 years.

prescribed for 24\% of patients with T2DM in Germany; among US veterans with diabetes mellitus (96\% men) $40-75$ years of age, lipid-lowering drugs were prescribed in $61 \%$ of primary prevention patients; and a total of $64 \%$ of patients with T2DM treated in primary care were prescribed lipid-lowering medicines in Australia. ${ }^{15} \mathrm{We}$ found at the beginning of the study that $35.8 \%$ were candidates for primary prevention with statins. The percentage of patients who need statins was maintained with $35.1 \%$ and $36.1 \%$ at 1-year and 2-year evaluations for primary prevention.

Past studies have reported statin adherence rates from $25 \%$ to $40 \% .{ }^{24}{ }^{25}$ Statin discontinuation (non-persistence) rates were based on real-world Dutch observational data. ${ }^{26}$ After 1 year, treatment persistence was $61.5 \%$; after 2 years, persistence was $47.7 \%$ for primary prevention patients and $57.7 \%$ for secondary prevention patients. After 1 year in the model, $38.5 \%$ of control patients 
discontinued statin therapy compared with $19.0 \%$ in the intervention group; after 2 years, statin discontinuation was $47.7 \%$ vs $23.3 \%$, respectively. ${ }^{27}$ In our study, adherence was $54 \%-67 \%$ in annual visits. A major cause of non-adherence was an economic issue $(52.04 \%)$. Among them, 46-55 years of age were highly adherent, males were more adherent to medication than females. ${ }^{4}$

A previous study from the National Diabetes Registry showed that lipid-lowering medications were prescribed for $70 \%$ of patients with T2DM with triglycerides $>350 \mathrm{mg} / \mathrm{dL} .{ }^{28}$ In our study, $13.9 \%$ had fibrates indicated when triglycerides were $>150 \mathrm{mg} / \mathrm{dL}$. Our study found that patients who abandoned treatment with fibrates at 2 years were younger. For the other evaluations, there was no significant difference in age or time of diagnosis of diabetes. In other studies, patients who did not abandon treatment were older, more concurrent cardiovascular medications, more time with diabetes and more preexisting or recently diagnosed cardiovascular diseases. ${ }^{5}$

The implementation of treatment guidelines in clinical practice is difficult. When a patient is diagnosed with T2DM, the guidelines recommend initiation of an extensive treatment regimen that includes several different medication classes. Patient perceptions of diabetes are influenced by the healthcare professionals they encounter. Clear communication between patient and provider is a predictor of good self-management, whereas poor communication is associated with poor treatment adherence. ${ }^{15}$ Barriers to achieving lipid control are low recognition by the healthcare professionals that dyslipidemia requires long-term management and inadequate knowledge of algorithms. We found that blood pressure (BP) and LDL-C, as well as combined BP and LDL-C goal attainment rates were the lowest in endocrine but highest in other departments. ${ }^{29}$ The use of statins and the lack of attention to LDL-C or adopting small doses for fear of side effects may be the reasons for the low LDL-C achievement rate. Most patients who should have received high-intensity therapy under the guidelines were treated appropriately $(n=544,72.2 \%)$. Adherence to the guideline recommendations among patients who received statin therapy was estimated as $72 \%$, while $28 \%$ $(\mathrm{n}=208)$ were non-adherent. Of the non-adherent, 126 $(16.7 \%)$ received less than the ideal therapy. We found that approximately one-third of patients received statin therapy at an inappropriate intensity according to the guideline recommendations. We observed underuse of appropriate statin therapy intensity based on the guideline recommendations, especially for primary prevention. $^{30}$

One of the strengths of this study is the ability to include information on new diagnoses and treatment that occurred after initiation of lipid-lowering therapy. Some limitations of this study are that we did not have information on the reason for treatment discontinuation from all patients, we only included patients with $<5$ years of diagnosis of diabetes, and patients with high cardiovascular risk were not included.

\section{CONCLUSION}

To obtain control goals, almost $88.2 \%$ of patients require lipid-lowering agents. In the long term, half of the patients who were indicated an St and those with St+Fib discontinued their lipid-lowering treatment. It is necessary to establish strategies to convince about the benefits of starting and maintaining therapy, both for patients and healthcare professionals.

\section{Author affiliations}

${ }^{1}$ Centro de Atención Integral del Paciente con Diabetes (CAIPaDi), Instituto Nacional de Ciencias Médicas y Nutrición Salvador Zubirán, Mexico City, Mexico

${ }^{2}$ Department of Endocrinology and Metabolism, Instituto Nacional de Ciencias Médicas y Nutrición Salvador Zubirán, Mexico City, Mexico

${ }^{3}$ Unidad de Investigación de Enfermedades Metabólicas, Instituto Nacional de Ciencias Médicas y Nutrición Salvador Zubirán, Mexico City, Mexico

${ }^{4}$ Tecnologico de Monterrey, Escuela de Medicina y Ciencias de la Salud, Monterrey, Mexico

${ }^{5}$ Dirección de Nutrición, Instituto Nacional de Ciencias Médicas y Nutrición Salvador Zubirán, Mexico City, Mexico

${ }^{6}$ Rollins School of Public Health, Emory University, Atlanta, Georgia, USA

Collaborators CAIPaDi Study Group: María Teresa Alcántara-Garcés, Denise Arcila-Martínez, Rodrigo Arizmendi-Rodríguez, Michelle Díaz-Pineda, Humberto Del Valle-Ramírez, Arturo Flores García, Adriana Galván-Pérez, Fernanda Garnica-Carrillo, Eduardo González-Flores, Mariana Granados-Arcos, Héctor Infanzón-Talango, María Victoria Landa-Anell, Arely López-Reyes, Marco Antonio Melgarejo-Hernández, Liliana Pérez-Peralta, Sofía Ríos-Villavicencio, David Rivera de la Parra, Francis Rojas-Torres, Sandra Sainos-Muñoz, Alejandra Sierra-Esquivel, María Luisa Velasco-Pérez, Héctor Velázquez-Jurado, Andrea Villegas-Narvaez, Luz Elena Urbina-Arronte, Verónica Zurita-Cortés, Francisco J Gómez-Pérez, David Kershenobich-Stalnikowitz.

Contributors Research idea and study design: SH-J, ACG-U; data acquisition: all healthcare professionals in the CAIPaDi Working Group; data analysis/ interpretation: SH-J, ACG-U, CAA-S; statistical analysis: ACG-U, FMDR-0; manuscript drafting: SH-J, ACG-U; supervision or mentorship: KMVN, CAA-S, KIG. Each author contributed important intellectual content during manuscript drafting or revision and accepts accountability for the overall work by ensuring that questions pertaining to the accuracy or integrity of any portion of the work are appropriately investigated and resolved.

Funding The CAIPaDi program has received grants from AstraZeneca, Fundación Conde de Valenciana, Novartis, Consejo Nacional de Ciencia y Tecnología ('Proyectos de Desarrollo Científico para Atender Problemas Nacionales' 2013 project 214718), Nutrición Médica y Tecnología, NovoNordisk, Boehringer Ingelheim, Dirección General de Calidad y Educación en Salud, Eli Lilly, Merck Serono, MSD, Silanes, Chinoin and Carlos Slim Health Institute. There are no other potential conflicts of interest relevant to this article.

Competing interests None declared.

Patient consent for publication Not required.

Ethics approval The CAIPaDi model was approved by the Institutional Ethics and Research Committees (Ref 1198) and registered in ClinicalTrials.gov (NCT02836808). All patients signed an informed consent form.

Provenance and peer review Not commissioned; externally peer reviewed.

Data availability statement All data relevant to the study are included in the article.

Open access This is an open access article distributed in accordance with the Creative Commons Attribution Non Commercial (CC BY-NC 4.0) license, which permits others to distribute, remix, adapt, build upon this work non-commercially, and license their derivative works on different terms, provided the original work is properly cited, appropriate credit is given, any changes made indicated, and the use is non-commercial. See: http://creativecommons.org/licenses/by-nc/4.0/.

ORCID iDs

Ana Cristina García-Ulloa http://orcid.org/0000-0003-0653-4938

Carlos Alberto Aguilar-Salinas http://orcid.org/0000-0001-8517-0241

K M Venkat Narayan http://orcid.org/0000-0001-8621-5405 


\section{REFERENCES}

1 Schofield JD, Liu Y, Rao-Balakrishna P, et al. Diabetes dyslipidemia. Diabetes Ther 2016;7:203-19.

2 van Driel ML, Morledge MD, Ulep R, et al. Cochrane corner: interventions to improve adherence to lipid-lowering medication. Heart 2018;104:367-9.

3 Zhao Y, Zabriski S, Bertram C. Associations between statin adherence level, health care costs, and utilization. J Manag Care Spec Pharm 2014;20:703-13.

4 Khatun A, Saha SK, Ajmery S, et al. Adherence pattern of lipid lowering drugs in a tertiary care hospital. Mymensingh Med $J$ 2017;26:266-71.

5 Yang C-C, Jick SS, Testa MA. Discontinuation and switching of therapy after initiation of lipid-lowering drugs: the effects of comorbidities and patient characteristics. Br J Clin Pharmacol 2003;56:84-91.

6 Peralta MR, Sánchez GB, Arias ER. Cardiovascular risk reduction: past, present and future in Mexico. Ann Clin Hypertens 2018;2:38-47.

7 Aguilar-Salinas CA, Gómez-Pérez FJ, Rull J, et al. Prevalencia de las dislipidemias en La Encuesta Nacional de Salud Y Nutrición 2006. Salud Publica Mex 2010;52:S44-53.

8 Rojas-Martínez R, Basto-Abreu A, Aguilar-Salinas CA, et al. Prevalencia de diabetes POR diagnóstico médico previo en México. Salud Publica Mex 2018;60:224-32.

9 Catapano AL, Graham I, De Backer G. 2016 ESC/EAS guidelines for the management of dyslipidemias. Rev Esp Cardiol 2017;70:115.e.

10 Grundy SM, Stone NJ, Bailey AL, et al. 2018 AHA/ACC/AACVPR/ AAPA/ABC/ACPM/ADA/AGS/APhA/ASPC/NLA/PCNA guideline on the management of blood cholesterol. J Am Coll Cardiol 2019;73:e285-350.

11 Blackburn DF, Dobson RT, Blackburn JL, et al. Adherence to statins, beta-blockers and angiotensin-converting enzyme inhibitors following a first cardiovascular event: a retrospective cohort study. Can J Cardiol 2005;21:485-8.

12 Simons LA, Levis G, Simons J. Apparent discontinuation rates in patients prescribed lipid-lowering drugs. Med J Aust 1996;164:208-11.

13 Avorn J, Monette J, Lacour A, et al. Persistence of use of lipidlowering medications. JAMA 1998;279:1458.

14 Turner RM, Yin P, Hanson A, et al. Investigating the prevalence, predictors, and prognosis of suboptimal statin use early after a non-ST elevation acute coronary syndrome. J Clin Lipidol 2017;11:204-14.

15 Karlsson SA, Franzén S, Svensson A-M, et al. Prescription of lipidlowering medications for patients with type 2 diabetes mellitus and risk-associated LDL cholesterol: a nationwide study of guideline adherence from the Swedish national diabetes register. BMC Health Serv Res 2018;18:1-10.

16 Hernández-Jiménez S, García-Ulloa C, Mehta R, et al. Innovative models for the empowerment of patients with type 2 diabetes: the CAIPaDi program. Recent Pat Endocr Metab Immune Drug Discov 2014;8:202-9.

17 Hernández-Jiménez S, García-Ulloa AC, Bello-Chavolla OY, et al. Long-Term effectiveness of a type 2 diabetes comprehensive care program. The CAIPaDi model. Diabetes Res Clin Pract 2019;151:128-37.

18 Hernández-Jiménez S, Aguilar-Salinas CA, García-Ulloa AC. Algoritmo de atención clínica. México. plan Estratégico sectorial para La Difusión E Implementación de Guías de Práctica Clínica. diabetes mellitus tipo 2. Secretaría de Salud, SEDENA, SEMAR 2018 http://www.incmnsz.mx/CAIPaDi/algoritmo.pdf 2018.

19 Stone NJ, Robinson JG, Lichtenstein AH. 2013 ACC/AHA hyperlipidemia guidelines. J Am Coll Cardiol 2014;63:2889-934.

20 American Diabetes Association. 10. Cardiovascular Disease and Risk Management: Standards of Medical Care in Diabetes-2019. Diabetes Care 2019;42:S103-23.

21 Benner JS, Glynn RJ, Mogun H, et al. Long-Term persistence in use of statin therapy in elderly patients. JAMA 2002;288:455-61.

22 Piwońska A, Piotrowski W, Kozela M, et al. Cardiovascular diseases prevention in Poland: results of WOBASZ and WOBASZ II studies. Kardiol Pol 2018;76:1534-41.

23 García Díaz E, Ramírez Medina D, Morera Porras Óscar Mauricio, et al. Determinantes de la inercia en El tratamiento hipolipidemiante de pacientes Con diabetes mellitus tipo 2. Endocrinología, Diabetes y Nutrición 2019;66:223-31.

24 Avorn J, Monette J, Lacour A, et al. Persistence of use of lipid-lowering medications: a cross-national study. JAMA 1998;279:1458-62.

25 Chan DC, Shrank WH, Cutler D, Patient CD, et al. Patient, physician, and payment predictors of statin adherence. Med Care 2010;48:196-202.

26 Mantel-Teeuwisse AK, Goettsch WG, Klungel OH, et al. Long term persistence with statin treatment in daily medical practice. Heart 2004;90:1065-6.

27 Vegter S, Oosterhof P, van Boven JFM, et al. Improving adherence to lipid-lowering therapy in a community pharmacy intervention program: a cost-effectiveness analysis. JMCP 2014;20:722-32.

28 Eriksson M, Zethelius B, Eeg-Olofsson $\mathrm{K}$, et al. Blood lipids in 75,048 type 2 diabetic patients: a population-based survey from the Swedish national diabetes register. Eur J Cardiovasc Prev Rehabil 2011;18:97-105.

29 Yan X, Li Y, Dong Y, et al. Blood pressure and low-density lipoprotein cholesterol control status in Chinese hypertensive dyslipidemia patients during lipid-lowering therapy. Lipids Health Dis 2019;18:1-11.

30 Alburikan KA, Asiri RM, Alhammad AM, et al. Utilization and adherence to guideline-recommended lipid-lowering therapy at an academic medical center. Ann Saudi Med 2017;37:276-81. 